\title{
Prophylactic Intramyometrial Oxytocin before Placenta Delivery during Cesarean Section Prevents Postpartum Hemorrhage: A Prospective Randomized Study of 150 Women
}

\author{
Divya Mangla, JK Goel, Ruchica Goel
}

\begin{abstract}
Objectives: To compare efficacy of intramyometrial oxytocin vs intravenous oxytocin infusion in reducing blood loss during cesarean section.

Materials and methods: A prospective randomized controlled trial of 150 women undergoing cesarean section was done. Women undergoing cesarean section were randomly divided into three groups according to method of administration of oxytocin. In group I $(n=50): 20$ units of oxytocin in $500 \mathrm{cc}$ of ringer lactate as continuous infusion I/V after separation of placenta was given. In group II $(n=50)$ : 5 units of oxytocin is diluted in 10 cc of normal saline and 5 cc injected in each cornu of uterus after separation of placenta. In group III $(n=50)$ : 5 units of oxytocin is diluted in $10 \mathrm{cc}$ of normal Saline and $5 \mathrm{cc}$ injected in each cornu of uterus before separation of placenta. Blood loss was calculated by number of mops soaked and amount of blood in suction jar.
\end{abstract}

Results: Average blood loss was found to be more in group I $606 \mathrm{cc}$, while in group II average blood loss was $460 \mathrm{ml}$ which further decreased to $412 \mathrm{cc}$ in group III. There was an additional observation that the $6 \%$ cases where I/V oxytocin infusion could not prevent uterine atony while immediate uterine contraction was achieved with intramyometrial oxytocin.

Conclusion: Intramyometrial injection of oxytocin when given before separation of placenta was found to be most effective method to increase uterine contraction, reducing incidence of postpartum hemorrhage and thus decreasing cesarean morbidity.

Keywords: Intramyometrial oxytocin, Cesarean, Postpartum hemorrhage.

How to cite this article: Mangla D, Goel J K, Goel R. Prophylactic Intramyometrial Oxytocin before Placenta Delivery during Cesarean Section Prevents Postpartum Hemorrhage: A Prospective Randomized Study of 150 Women . J South Asian Feder Obst G ynae 2012;4(2):93-96.

Source of support: Nil

Conflict of interest: None

\section{INTRODUCTION}

Globally about $11 \%$ of women having live birth have severe postpartum hemorrhage (PPH) amounting to 14 million women a year. ${ }^{1} \mathrm{M}$ ajor burden of this is born by women in underdeveloped and developing countries. The incidence of PPH is 3 to $6 \%$ of all normal deliveries. ${ }^{2}$ The incidence is higher in operative deliveries specially, so when conducted under general anesthesia, being $3.9 \%$ in vaginal delivery and $6.4 \%$ in cesarean deliveries. ${ }^{3}$ U terine atony is the main cause of $\mathrm{PPH} .{ }^{4} \mathrm{U}$ terine atony is one of the most common indications for cesarean or postpartum hysterectomy. ${ }^{5}$ Poor access to transport system and emergency services, shelled health workers, along with anemia and poor nutritional status adds to its severity. In India, the incidence of maternal death ranges from 11.7 to $25.87 \%$. ${ }^{6-8} \mathrm{To}$ prevent PPH active management of third-stage now has become the rule. A mong uterotonics, oxytocin has proven to be very effective in reducing the incidence of $\mathrm{PPH}$ and prolonged third stage of labor. ${ }^{9}$ Route of administration of oxytocin can be intravenous (I/V), intramuscular (I/M), intravenous continuous infusion, intramyometrial (IMM) or intraumbilical during cesarean section. In case of PPH direct injection into uterus either transvaginally or transabdominally, following a vaginal birth or directly at cesarean delivery, has proven effective. The effect of oxytocin on the uterus is marked in late pregnancy and during labor. It is believed that development of oxytocin receptors in the myometrium commences around 20th week of gestation. Sensitivity of the myometrium to the circulating oxytocin increases with advancing gestation and peaks at parturition. ${ }^{10}$ I/V infusion can cause water intoxication, hypotention, tachycardia and it al so increases incidence of per and postoperative nausea and vomiting.

The aim of this study was to assess the efficacy of intramyometrial oxytocin (5 units in 10 cc of normal saline) in decreasing blood loss and preventing postpartum hemorrhage during cesarean section.

\section{MATERIALS AND METHODS}

The study was a randomized prospective study which was conducted at Department of Obstetrics and Gynecology, Shri MP Shah Medical College, Guru Gobind Singh Hospital, Jamnagar, Gujarat. It included 150 women operated by lower segment cesarean section which were taken randomly. They were evaluated by a detailed history and thorough clinical examination. A ny associated maternal risk factors were also recorded. Labor events followed by indication for L SCS were recorded. Women were divided randomly into three groups according to route of oxytocin administration during cesarean section, as shown in Table 1.

Antacids and antiemetics were given to all women of cesarean section by the anesthetists before induction. M ode of anesthesia was decided by anesthetist as per individual case (spinal or GA).

The effects of these three regimens were recorded by following parameters:

1. U terus was assessed for its contractility by the method of palpation by the attending surgeon.

2. Blood loss during the operation was estimated by volume of blood mixed with amniotic fluid in the graduated suction 


\begin{tabular}{lll} 
& \multicolumn{2}{c}{ Table 1: Grouping of women } \\
\hline Group I $(n=50)$ & Group 2 $(n=50)$ & Group 3 ( $n=50)$ \\
\hline $\begin{array}{l}\text { Continuous intravenous oxytocin } \\
\text { infusion ( } 20 \text { units in } 500 \mathrm{ml} \text { of }\end{array}$ & Intramyometrial oxytocin after & Intramyometrial oxytocin before \\
ringer lactate) & placental separation (5 units diluted & placental separation (5 units diluted up to \\
& $\begin{array}{l}\text { up to } 10 \mathrm{ml} \text { of NS) } \\
\text { (IMM after) (Fig. 1) }\end{array}$ & 10 ml of NS) (IMM before) (Fig. 2) \\
\hline
\end{tabular}

jar and the number of sponges soaked with blood, amount of bleeding per vaginum was also noted during 1st hour after operation.

3. Need for extra dose of antiemetic was recorded in each group.

4. Baseline systolic blood pressure was obtained prior to uterine incision by attending anesthetist. Systolic blood pressure was recorded after injection of study solutions for 15 minutes at intervals of 5 minutes each.

Postoperatively patient was reassessed for her general condition, hemoglobin, etc. B aby outcome was also recorded.

\section{OBSERVATIONS}

In our study though in most of the women I/V infusion and intramyometrial injection of oxytocin resulted in similar effective uterine contractions yet in three women of group I where I/V infusion failed to contract uterus, an intramyometrial injection given in these women got uterus contracted immediately.

The blood loss in various groups was compared, as shown in Table 2. In group I, maximum number of women, i.e. $60 \%$ had blood loss ranging from 501 to $700 \mathrm{cc}$ followed by $20 \%$ in the range of 301 to $500 \mathrm{cc}$. Fourteen percent women had blood loss in the range of 701 to $900 \mathrm{cc}$ and in $6 \%$ blood loss was more than $900 \mathrm{cc}$. In group II, 70\% of the women had blood loss in the range of 301 to $500 \mathrm{cc}$ followed by $18 \%$ in range of 501 to $700 \mathrm{cc}$, none had blood loss $>900 \mathrm{cc}$. In group III, 72\% of the women had blood loss in the range of 301 to $500 \mathrm{cc}$ while $14 \%$ women had blood loss in the range of 501 to 700 cc; only one patient had blood loss more than $700 \mathrm{cc}$.
A verage blood loss in group I was $606 \mathrm{ml}$, group II was $460 \mathrm{ml}$ and group III was $412 \mathrm{ml}$ as shown in Graph 1.

Comparison of peroperative requirement of additional antiemetics was also done among three groups and it was observed that in group I, $20 \%$ of the women required additional antiemetics because of peroperative nausea and vomiting while in groups II and III, only $2 \%$ of women required additional antiemetics.

Changes in systolic blood pressure were noted and compared in various groups, as shown in Table 3 . Systolic blood pressure was found to decrease in all groups but maximum decrease was found in group I. Sixty-two percent women in group 1 showed the decrease in systolic blood pressure in the range of

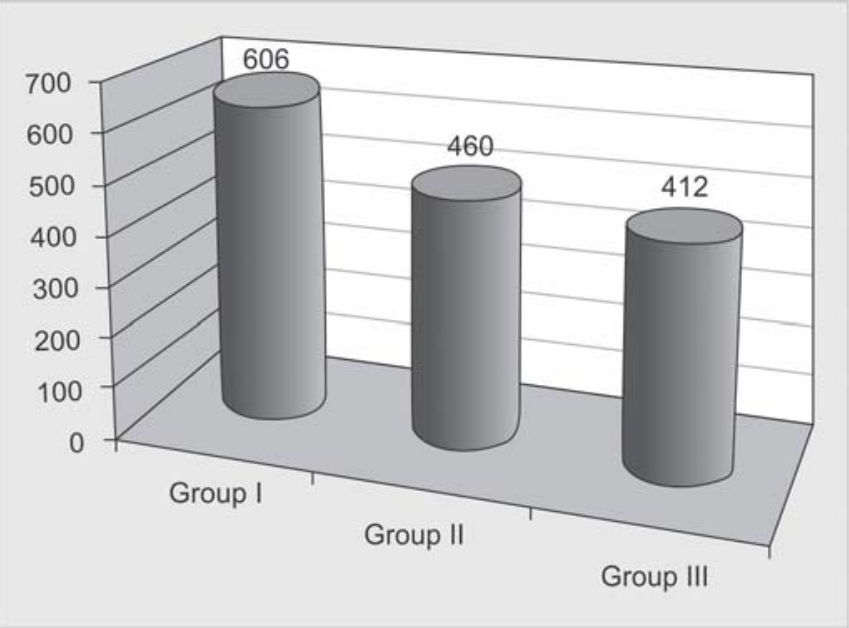

Graph 1: Average blood loss ( $\mathrm{ml})$ in various groups

Table 2: Comparison of blood loss in various groups

\begin{tabular}{|c|c|c|c|c|c|c|}
\hline \multirow[t]{2}{*}{ Blood loss (ml) } & \multicolumn{2}{|c|}{ Group 1 (IV infusion) } & \multicolumn{2}{|c|}{ Group 2 (IMM after) } & \multicolumn{2}{|c|}{ Group 3 (IMM before) } \\
\hline & $n=50$ & $\%$ & $n=50$ & $\%$ & $n=50$ & $\%$ \\
\hline$\leq 100$ & 0 & 0 & 0 & 0 & 0 & 0 \\
\hline $101-300$ & 0 & 0 & 2 & 4 & 6 & 12 \\
\hline $301-500$ & 10 & 20 & 35 & 70 & 36 & 72 \\
\hline $501-700$ & 30 & 60 & 9 & 18 & 7 & 14 \\
\hline $701-900$ & 7 & 14 & 4 & 8 & 1 & 2 \\
\hline$>900$ & 3 & 6 & 0 & 0 & 0 & 0 \\
\hline
\end{tabular}

\begin{tabular}{|c|c|c|c|c|c|c|}
\hline \multirow{2}{*}{$\begin{array}{l}\text { Systolic BP } \\
(\mathrm{mm} \mathrm{Hg})\end{array}$} & \multicolumn{2}{|c|}{ Group I } & \multicolumn{2}{|c|}{ Group 2} & \multicolumn{2}{|c|}{ Group 3} \\
\hline & $n=50$ & $\%$ & $n=50$ & $\%$ & $n=50$ & $\%$ \\
\hline 00 & 00 & 00 & 11 & 22 & 10 & 20 \\
\hline $1-5$ & 2 & 4 & 36 & 72 & 39 & 78 \\
\hline $6-10$ & 31 & 62 & 1 & 2 & 1 & 2 \\
\hline $11-15$ & 10 & 20 & 1 & 2 & 0 & 0 \\
\hline $16-20$ & 6 & 12 & 1 & 2 & 0 & 0 \\
\hline$>20$ & 1 & 2 & 0 & 0 & 0 & 0 \\
\hline
\end{tabular}


Prophylactic Intramyometrial Oxytocin before Placenta Delivery during Cesarean Section Prevents Postpartum Hemorrhage

6 to $10 \mathrm{~mm} \mathrm{Hg}$, while $20 \%$ women showed decrease in systolic blood pressure in the range of 11 to $15 \mathrm{~mm} \mathrm{Hg},>20 \mathrm{~mm} \mathrm{Hg}$ fall was also observed in $2 \%$ women. In groups II and III maximum number of women showed decreased in systolic B $P$ in the range of 1 to $5 \mathrm{~mm} \mathrm{Hg}$ while in $20 \%$ of the women no change in blood pressure was found at all.

\section{DISCUSSION}

The observation of failure of uterus to contract in $6 \%$ of the cases of group I and resulting in immediate effective uterine contraction after intramyometrial injection in these cases is statistically borderline significanct with a p-value of 0.047 .

Blood loss during cesarean delivery occurs from incision through the abdominal wall, myometrium and the placental bed. Oxytocin is commonly administered after cesarean delivery to promote uterine contraction, thus reducing blood loss from the myometrium and the placental site. Hayashi $\mathrm{RH}$ et al ${ }^{11}$ demonstrated that effective pharmacological treatment of uterine atony is often achieved by an intramyometrial injection of PGF $2 \alpha .250 \mu \mathrm{g}$.

Our data indicated that 5 IU oxytocin (group III) given intramyometrial before the separation of placenta results in considerable decrease in estimated blood loss at cesarean delivery than does 5 unit oxytocin intramyometrial after separation of placenta (group II) and $20 \mathrm{IU}$, continuous oxytocin

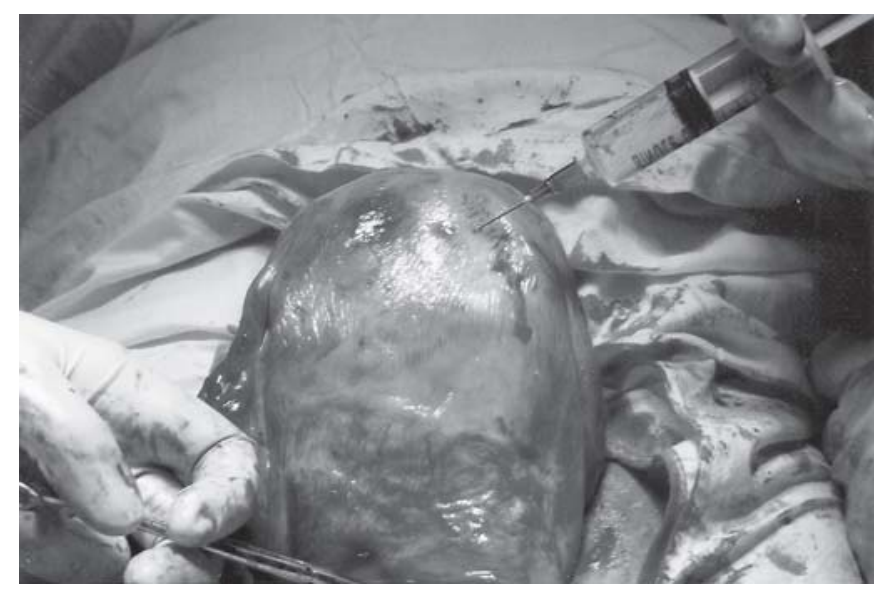

Fig. 1: Intramyometrial oxytocin after placental separation

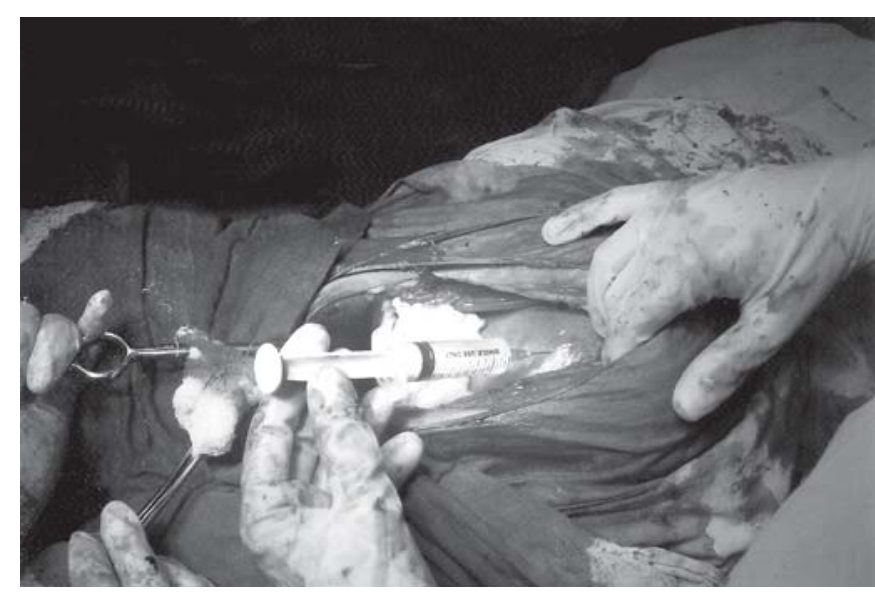

Fig. 2: Intramyometrial oxytocin before placental separation infusion (group I), which is statistically highly significant $(p=0.0001)$.

Catanzarite V $\mathrm{A}^{12}$ did not find any difference in estimated blood loss during elective cesarean section between parturients who received $20 \mathrm{IU}$ oxytocin intramyometrial and women who received $250 \mu \mathrm{g}$ intramyometrial injections at this dose for routine cesarean section.

Sarna et $\mathrm{al}^{13}$ determined that uterine contractility and estimated blood loss was similar following 5 or 20 IU of oxytocin I/V , thus indicating that there is no benefit on uterine tone and blood loss of administering more than 5 IU oxytocin during elective cesarean section.

The observation of the systemic side effects of IV oxytocin infusion in group I was responsible for nausea and vomiting, whereas IM M oxytocin as given in groups II and III acts locally and the systemic side effects of IV oxytocin can be prevented by intramyometrial oxytocin thus, reducing the complication during cesarean delivery due to aspiration of vomitus which is statistically significant ( $p=0.002)$.

The observation on hemodynamic changes in the form of decrease in blood pressure/tachycardia from baseline was less after intramyometrial injection than I/V administration.

The results of our study indicate that intramyometrial injection of $5 \mathrm{IU}$ oxytocin after cesarean delivery is associated with a lesser decrease in blood pressure than 20 unit I/V oxytocin (continuous infusion) which is statistically highly significant $(p=0.0001)$.

It is well known that I/V bolus injection of oxytocin may result in short lived hypotension in nonpregnant women, during pregnancy and after cesarean delivery. ${ }^{14}$ The etiology of the observed hemodynamic changes is controversial and most likely multifactorial.

Kelvin C Dennehy et al ${ }^{15}$ determined blood pressure following intravenous and intramyometrial injection of oxytocin after cesarean delivery and observed that intramyometrial administration of $20 \mathrm{IU}$ oxytocin after cesarean delivery is associated with more severe hypotension than is IV injection of 5 IU oxytocin. They stated that they did not expect intramyometrial oxytocin to be associated with more severe hypotension. According to them the most likely explanation for this finding is that intramyometrial oxytocin injecton results in extensive rapid absorption of oxytocin from the myometrium into the systemic circulation.

The reason for difference in results of their study and our study may be due to the different dose of oxytocin used, i.e. 20 IU in their study and 5 IU in our study for intramyometrial injection.

In our experience, instituting prophylactic intramyometrial injection of oxytocin as soon as the baby is delivered has been associated with reduced average blood loss, lesser decrease in systolic blood pressure and less need for additional antiemetics.

\section{CONCLUSION}

To conclude, oxytocin remains the first-line drug in the prevention of uterine atonia in parturients undergoing cesarean section, especially due to its high therapeutic index. To reduce 
the incidence of postpartum hemorrhage, its prophylactic use is justified. Regarding the route of administration, prophylactic intramyometrial oxytocin before delivery of placenta seems to increase uterine contractibility and reducing the blood loss during cesarean delivery and thus decreasing cesarean morbidity. There is less need for antiemetics and there are less hemodynamic changes, i.e. hypotension and tachycardia which can be detrimental in women with low cardiac reserve or hypovolemia.

\section{REFERENCES}

1. A bou-Zahr C. The global burden of maternal death and disability. BrM ed Bull 2003;67:1-11.

2. Desai SV, Jani NS. Postpartum hemorrhage in pregnancy induced hypertension. In: Shah M R (Ed). Hypertensive disorders in pregnancy. N ew Delhi. JP B ros 2007.

3. Parikh M N. Introduction PPH. Fogsi focus 2007:1-2.

4. Clark SL, Sze-Y a Y , Phelan JP, B ruce SR, Paul RH. Emergency hysterectomy for obstetric haemorrhage. Obstet Gynaecol 1984;64:376-80.

5. Kastner ES, Figueroa R, et al. Emergency peripartum hysterectomy: Experience at a community teaching hospital. Obstet Gynecol 2002;99:971-80.

6. Mukherjee J, Ganguly RP, Saha SK. M aternal mortality due to hemorrhage with emphasis on PPH. J Obstet Gynecol India 2001;51(5):130-33.

7. Patel DA, Gangopadhyaya SB, V aishnav SB, Shrivastava RG, $R$ ajagopalan $R$. M aternal mortality at $K$ aramsad. The only rural medical college of Gujarat (J anuary 1994 to Dec. 1997). J Obstet Gynecol India 2001;51(1):63-66.

8. Bedi M, Kambo I, Dhillon BS, Saxena BH, Singh P. M aternal deaths in India - Preventable tragedies. J Obstet Gynecol India 2001;51(2):86-92.

9. Nordstorm L, et al. R outine oxytocin in 3rd stage of labor. A placebo controlled randomized trial. B r J of Obst and Gynecol 1997;104:781-86.
10. Fuchs $A R$, Husslein $P$, et al. Oxytocin and initiation of human parturition, Stimulation of prostaglandin production in human deciduas by oxytocin. A m J O bstet Gynecol 1981;141:694.

11. Hayashi RH, Castillo M S. M anagement of severe postpartum hemorrhage due to uterine atony using an analogue of prostaglandin F2 alpha. Obstet Gynecol 1981;58:426-29.

12. Catanzarite VA. Prophylactic intramyometrial carboprost tromethamine does not substantially reduce blood loss relative to intramyometrial oxytocin at routine caesarean section. A m J Perinatol 1990;7:39-42.

13. Sarna M C, Soni AK . Intravenous oxytocin in w omen undergoing el ective caesarean section. A nesth A nalog 1997;84:753-56.

14. A nderson TW, et al. Cardiovascular effects of rapid intravenous injection of synthetic oxytocin during el ective caesarean section. Clin Pharm Ther 1965;6:345-49.

15. K elvin C. Dennehy, Ola P Rosaeg, et al. Oxytocin injection after caesarean delivery - Intravenous or intramyometrial?. Can J A naesth 1998;45(7):635-39.

\section{ABOUT THE AUTHORS \\ Divya Mangla (Corresponding Author)}

A ssistant Professor, D epartment of O bstetrics and Gynecology, Subharti M edical College, Bye-Pass Road, M eerut-250002, Uttar Pradesh, India Phone: 09758852575, e-mail: drdivyagoel@ rediffmail.com

\section{JK Goel}

A ssociate Professor, D epartment of O bstetrics and Gynecology, Shri Ram M urti Smark Institute of Medical Sciences, Bareilly, Uttar Pradesh, India

\section{Ruchica Goel}

Senior R esident, Department of O bstetrics and Gynecology, Shri Ram M urti Smarak Institute of M edical Sciences, Bareilly, U ttar Pradesh India 